This item was submitted to Loughborough's Research Repository by the author.

Items in Figshare are protected by copyright, with all rights reserved, unless otherwise indicated.

\title{
The development of a European fatal accident database
}

PLEASE CITE THE PUBLISHED VERSION

PUBLISHER

ICrash 2008

LICENCE

CC BY-NC-ND 4.0

\section{REPOSITORY RECORD}

Morris, Andrew, Charlotte L. Brace, Steven Reed, Helen Fagerlind, Karolina Bjorkman, Michael Jaensch, Dietmar Otte, et al.. 2019. "The Development of a European Fatal Accident Database". figshare. https://hdl.handle.net/2134/4603. 
This item was submitted to Loughborough's Institutional Repository (https://dspace.lboro.ac.uk/) by the author and is made available under the following Creative Commons Licence conditions.

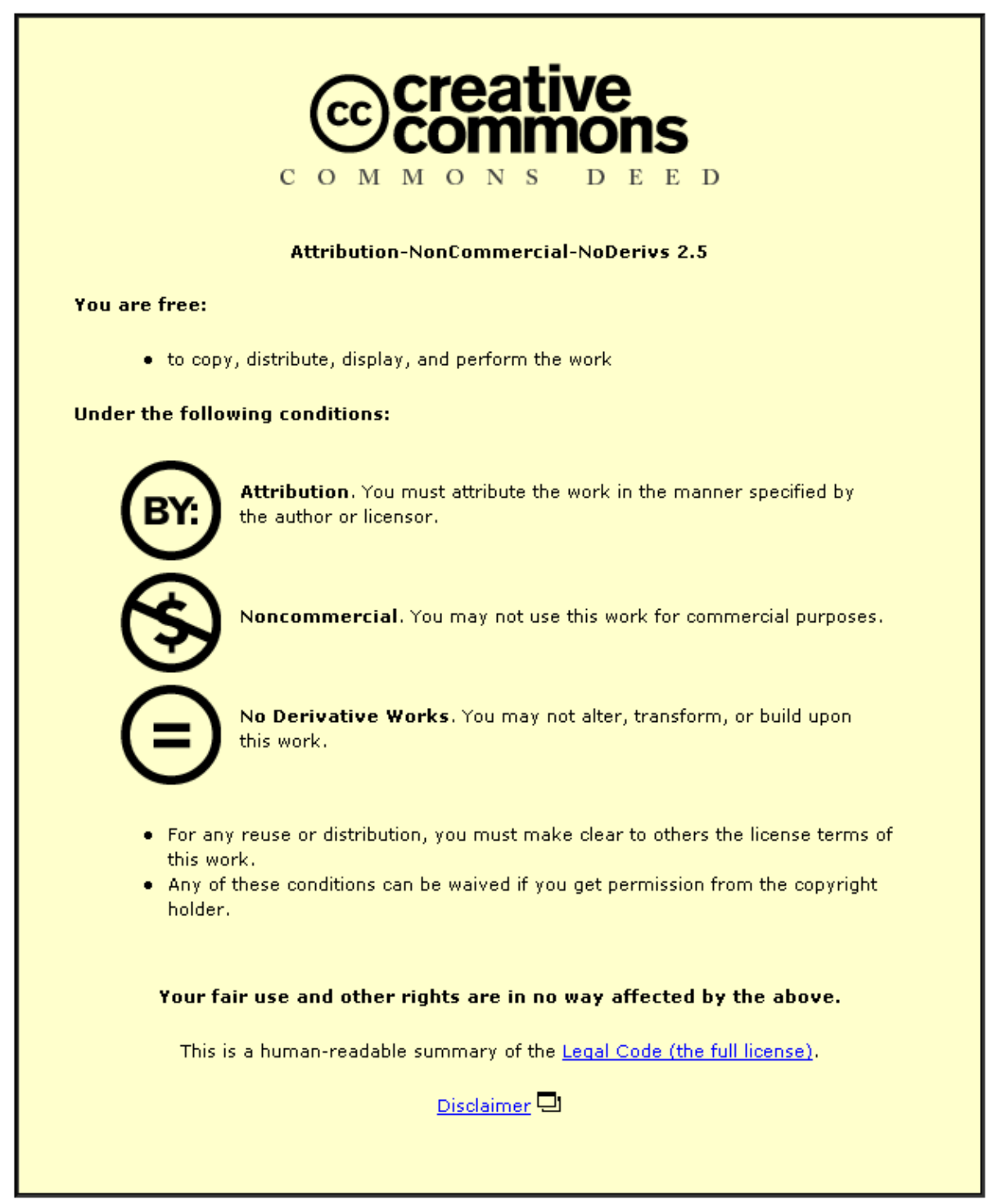

For the full text of this licence, please go to: http://creativecommons.org/licenses/by-nc-nd/2.5/ 


\title{
The Development of a European Fatal Accident Database
}

\author{
Andrew Morris, Charlotte Brace and Steven Reed \\ Vehicle Safety Research Centre, Ergonomics and Safety Research Institute, Holywell Way, \\ Loughborough LE11 3UZ, UK www.esri.org.uk
Helen Fagerlind, , Karolina Bjorkman, Michael Jaensch, Dietmar Otte, Gilles Vallet, Lindsay Cant, Gabriele Giustiniani, Kalle Parkkari, Ernst Verschragen, Boudewijn Hoogvelt
SafetyNet WP5 Consortium http://www.erso.eu

\author{
Keywords: European Fatal Crash Database, Crash causation,
}

\begin{abstract}
A lack of representative European accident data to aid the development of safety policy, regulation and technological advancement is a major obstacle in the European Union. Data are needed to assess the performance of road and vehicle safety and is also needed to support the development of further actions by stakeholders. A recent analysis conducted by the European Transport Safety Council identified that there was no single system in place that could meet all of the needs and that there were major gaps including indepth crash causation information. This paper describes the process of developing a data collection and analysis system designed to partly fill these gaps. A project team with members from 7 countries was set up to devise appropriate variable lists to collect fatal crash data under the following topic levels: accident, road environment, vehicle, and road user, using retrospective detailed police reports $(n=1,300)$. The typical level of detail recorded was a minimum of 150 variables for each accident. The project will enable multidisciplinary information on the circumstances of fatal crashes to be interpreted to provide information on a range of causal factors and events surrounding the collisions. This has major applications in the areas of active safety systems, infrastructure and road safety, as well as for tailoring behavioural interventions.
\end{abstract}

\section{INTRODUCTION}

Each year within the European Union (EU-15), there are approximately 40,000 people killed on the roads and over 1.7 million people injured (European Commission, 2005a). Such incidents cost the Community over 180 billion Euros annually, equal to 2\% of the EU's Gross National Product (GNP). With the growth in the number of EU member states (to EU-25), the European road death toll is set to increase to even more dramatic heights. To put these figures into perspective, "road crashes are the second most serious cause of death and hospital admission for EU citizens, preceded by cancer and followed by coronary heart disease" and for Europeans under 45 years of age, road crashes are the largest single cause of death (ETSC, 1999).

The number of people killed and injured on the roads started to decrease considerably from 2002 onwards (European Commission, 2005b), with improvements year on year for 2003 and 2004. However, there has not been such steep decline in the overall number of crashes. Incidents are still occurring frequently, although improvements in vehicle design and trauma management have helped to reduce the severity of injuries to the people involved in accidents, the number of slight injuries has not decreased. Despite these improvements in injury outcomes, it is estimated that $97 \%$ of all socioeconomic costs for transport crashes within the EU are as a result of those on the roads, and that $97 \%$ of the transport related fatalities occur in the road sector (ETSC, 1997).

\subsection{The perspective of one European country}


This section is used to set the scene for a 'good practice' European country. The existing accident statistics and processes for collecting and examining data from crashes are described so that the reader can fully understand the implications of the multidisciplinary project that is presented in this paper.

Accident statistics. Britain has had -relatively speaking- remarkable success in reducing road casualties, despite the vast growth in traffic since the beginning of the last century. In 1930 there were only 2.3 million motor vehicles in Great Britain, but over 7,000 people were killed in road crashes. Today, there are over 27 million vehicles on the roads but far fewer road deaths. In 1987 a target was set to reduce road casualties by one-third by 2000 compared with the average for 1981-85. Britain has more than achieved this target for reducing deaths and serious injuries. Road deaths have fallen by $39 \%$ and serious injuries by $45 \%$ and the UK is now one of the safest countries in Europe (and indeed the world). The British government launched a new 10-year target for road safety in 2000 to help focus on achieving a further substantial improvement in road safety by the year 2010 .

Routine practice. When a road crash occurs, the police conduct investigations of varying levels of detail, dependent on the nature of the incident outcome. Upon notification of non-fatal road accidents, an investigation dependent on the concerns of the officers involved, the severity of the accident outcome, and the size of the incident, is conducted. Whenever they are informed of, or attend a road traffic accident in which a person is killed or injured, the police complete an accident record, and upon verification, the information is transferred to a STATS19 form for input to the accident database of that police force. Data is used from STATS19 at a local level by engineers who look for indications of causation to design remedial measures, and nationally by policy-makers. The Department for Transport (DfT) compiles the national STATS19 data on personal injury road accidents, resulting casualties, and the vehicles involved. Personal injury road accidents statistics were first collected in 1909. This modern system of collecting information on injury accidents (STATS19) was introduced in 1949. The current system was established in 1979 following a wide ranging review. Subsequently the survey has been reviewed every 5 years to check that the data collected remain relevant. Following the 1997 Review of Collection of Road Accident Statistics a substantially revised data collection form was introduced in January 2005. This collects more detailed information indicating the precipitating and contributory factors which lead to a crash. The DfT make the national STATS19 data available by three main areas:

1. Accidents - including the severity of the accident, the number of vehicles and casualties involved, time and location, road class and number, speed limit, weather and road conditions, and carriageway hazards;

2. Vehicles - including type, location and manoeuvre at time of accident, and details of the driver (age, sex and breath test results);

3. Casualties - age, gender, injury severity and whether a driver, passenger or pedestrian.

Data are collected on a monthly basis from police forces throughout the year and are available for Great Britain, country region and county. Unless there has been a fatality or a serious "threat to life", it is subjective as to what level of detail the police investigation goes into. It could be suggested that more attention is given to cases where children are involved due to the empathic nature of the situation.

For fatal road accidents, the guidelines elaborated in the Road Death Investigation Manual (Association for Chief Police Officers, 2004) are followed. These detail how to undertake the investigation and are a "set of criteria...to enable the police service to work to a consistent standard of professional investigation”. A detailed report combining information from witnesses and the police investigation is produced on a routine basis for fatal road accidents. This report is used within the judicial process for examining criminal offences.

The national road accident statistics are collected and published, partly to inform public debate and partly to provide the basis for determining and monitoring effective road safety policies. It should be noted that there is little under-reporting with regard to fatal accidents, there is evidence that may be 
wide-spread under-reporting of non-fatal accidents (GRPS, 2006). Additionally, studies have also shown that the police tend to underestimate the severity of injury because of the difficulties in distinguishing severity at the scene of the accident, and that reporting rates are lower for the more vulnerable road users groups (Nakahara and Wakai, 2001).

\subsection{Effective development of countermeasures}

The EU target of a 50\% reduction in fatalities on the roads by 2010 (European Commission 2005a) will only be achieved by the introduction of the most effective countermeasures. It relies on the existence of basic knowledge of crashes and their causation and the availability of road safety data to monitor and assess performance. Reduction of road casualties through vehicle design is typically achieved by taking an 'Active' or 'Passive' safety approach. Passive safety normally involves the implementation of safety technology within the vehicle which is specifically designed to reduce injuries in the event of a crash; airbags and advanced seat belt technology are prime examples of such devices. In more recent times, there has been much activity and research in the field of 'Active safety'. This approach is traditionally associated with technologies that are likely to result in crash avoidance and such technologies include Intelligent Speed Adaptation (ISA), Enhanced Stability Programmes (ESP) and Lane Departure Warnings (LDW). These technologies are implemented into the vehicle as information and control devices with the specific intention of ensuring that every measure is taken to prevent the crash from happening in the first place. Most modern vehicles are equipped with a suitable range of both Passive and Active safety devices such that if the Active safety measures are ineffective and a crash becomes inevitable, a level of protection of the occupants can be assured in the crash through deployment of the Passive safety systems.

Accompanying the development of Active safety systems is recognition of the need for good quality representative crash causation data within the European Union so that such technology can evolve with specific consideration to the nature, circumstances and causes of real-world crashes. However, not only are data required for technological development they are also seen as essential for the purposes of the development of safety policy and monitoring of regulation within Europe. Data are needed to both assess the performance of road safety stakeholders and also to support the development of further actions. An analysis conducted by the European Transport Safety Council (ETSC, 2001) identified that no single crash database could meet all of the needs and that there were in fact still major gaps particularly in respect of both in-depth crash and injury causation. Specific policy questions at EU level include the role of infrastructure in crash causation, the monitoring of progress towards the 2010 casualty reduction targets and in particular, the role of vehicle and road design in crash and injury causation.

\subsection{Developing a multidisciplinary system to understand causal factors in road crashes}

The EC's $6^{\text {th }}$ Framework project SafetyNet - Building the Road Safety Observatory (Thomas et al, 2005) was formulated in part to address the need for a range of in-depth crash data (including accident causation). SafetyNet broadly comprises 7 major elements (Work Packages) and one of these elements (Work Package 5) has produced road crash data collection processes which deal mainly with the causation of crashes in the EU. It has also attempted to meet some requirements of the eSafety initiative and to tie in with existing European projects where harmonies exist. Therefore, WP 5 of SafetyNet is divided into two main tasks: the development of a European fatal crash data collection process and; the development of a European crash causation data collection process. The development and design of the first of these two processes is discussed in this paper.

\section{SYSTEM DEVELOPMENT}




\subsection{European Fatal Crash Data Collection Process and Data Resource - Examination of fatal crash causation using retrospective techniques}

The main purpose of the task was to build an effective data gathering structure to ensure that specific data on fatal crashes can be gathered in a systematic and routine manner, with a bias towards understanding and recording crash causation to assist in the development of countermeasures. The data has been collected using completely compatible methods although there may have been variations between teams according to differences in local infrastructure. This activity has included the development of a broad ranging intermediate level, fatal crash database by obtaining reports of police fatal crash investigations from a number of EU Member States (including France, Germany, Finland, The Netherlands, United Kingdom, Italy and Sweden). The data itself is of an intermediate level of detail but covering a representative sample of fatal crashes in each country. There have been no new investigations but research teams from each partner country have brought together available information from within the existing police and other emergency services structure. The information provided in the database has provided enhanced knowledge of the factors involved in fatal crashes at EU level and has made good use of the detailed information collected in the police fatal investigations. The dataset has been systematically selected according to a defined sampling plan and the data are representative of the countries in which the data are collected. The main data collection period involved a representative sample of between $2 \%$ and $10 \%$ of the fatal crashes in each country covered, depending on the magnitude of the fatal crash population. In all, 1300 fatal accident cases, involving at least 1 fatality per crash, were collated and analysed. These data describe the environmental factors, vehicle and driver factors to provide a description of the whole crash. Specific areas of data describe the overall crash circumstances, driver and vehicle characteristics, specific road infrastructure features, and descriptions of other crash participants.

Establishing the needs of data users. Before any development work commenced, a workshop was held entitled Establishing Requirements for New European In-Depth Crash Causation Information. The aim of this workshop was to provide the future users of crash data the opportunity to feed into the process of identifying general and specific research and policy questions which future crash data will be expected to address. A report was produced to summarise the workshop (SafetyNet, 2004) which focussed on the issues raised during the workshop session on the general and specific requirements for crash causation information and the subsequent feedback session on this topic. The feedback/research questions from the workshop were constantly referred to whilst developing the data variables to ensure consistency with user needs.

Data requirements were additionally sought from Road and Vehicle Safety National Experts in the EU25 Member States. Information and background on the project were presented to the National Experts and their feedback requested on data needs and requirements according to the nature of the project. All feedback was taken on board during the variable development process.

Variable development and protocols. An evaluation of the data gathering possibilities and the level of support from police, local and national administrations relating to access to current and recent fatal crashes was undertaken. Specific issues to be addressed locally e.g. legal, personal data, administrative and ethical considerations were identified. Specification of sampling region and criteria and specific data gathering methods were determined and a sampling methodology was implemented in each data collection region to ensure compatibility and linkage to national crash population (CARE). To start this process, a review of the existing procedures and protocols in EU Member States and the US was undertaken to ensure that the project would benefit from best practice. Existing procedures and protocols that were examined in detail included the UK Cooperative Crash Injury Study (CCIS), the UK On-the-Spot Project (OTS), the German In-Depth Accident Study (GIDAS), the US Fatal Accident Reporting System (FARS), and the Swedish Factors Influencing the Causation of Accidents and Incidents project (FICA). An initial data variable list was produced containing 1138 variables. This was reviewed and exclusions were made for variables that were outside the project objectives, e.g. injury related criteria. After close examination of the remaining 193 potential data variables, a 
provisional variable compilation list ensued. In order to determine which variables should be collected in the database, each variable was discussed in turn under the main headings of accident level, roadway level, vehicle level, and road user level. WP5 partners reviewed the provisional variable list during email circulation and at technical meetings. Each variable on the list was reviewed by each partner in collaboration with their infrastructure collaborators. This process included discussions for each variable's inclusion and definition, and partners' comments regarding possible problems with the collection of particular variables. The list received numerous iterations in accordance with the objectives of the project and the needs of the data users.

Data and data levels. The data recorded describes the environmental (including road infrastructure, e.g. crash barriers, road signs etc.), vehicle and driver factors to provide a description of the whole crash. In total approximately 150 variables were collected for each case with approximately 500 pieces of information per case being obtained. The data was not selected according to a "lowest common denominator" approach; instead partners were challenged to gather a variety of information types. Additional interpretative information was also required including a basic list of causation factors. It is anticipated that the data could be used by a multitude of stakeholders in the road transport system but specifically road infrastructure experts, highway engineers and vehicles designers. The data should be used to evaluate trends and to conduct inter-country comparisons where possible. There could be a future link to national activities since most safety actions take place under subsidiary concerns.

Training. A training course was developed and presented for data gathering groups to ensure harmonised, compatible procedures for gathering of data. This was followed by a trial data gathering exercise used to examine the viability of each local system and to validate overall methodologies and procedures. This stage was conducted over a 2-month period and additionally used to determine the final costs per case and the total case numbers to be gathered. A thorough review of procedures was then undertaken and used to assess proposed data gathering practises, and make amendments to procedures.

Data collection and use. Data collection activity commenced in February 2007 and was completed by March 2008. In total, approximately 1300 sets of fatal crash data were gathered over one year and entered onto a database. Data analysis and reporting are now underway in accordance with the designated plan of action developed in line with EC priorities. The independent fatal crash database will primarily be directed to policy support in the areas of responsibility of the EC and there will be a dialogue to ensure that their needs are being addressed.

\section{SELECTED RESULTS OF DATABASE ANALYSIS}

In this section, some SELECTED results from the database are shown. It is stressed that the data collection has only recently been completed and therefore in essence, analysis of the data is a relatively recent activity. However, overviews of the resultant database are now available and more rigorous statistical analyses will be reported on at a later date.

Table 1 shows the composition of the resultant database in terms of the vehicles and the road-users involved. By far the largest sub-group within the database were the passenger cars and their occupants which comprised $57 \%$ of the 'vehicles' grouping and $65 \%$ of the road-user groupings.

\begin{tabular}{|c|c|c|}
\hline \multicolumn{3}{|c|}{ Total cases 1296} \\
\hline & & Road Users \\
\hline Car & 1340 & 2249 \\
\hline Motorcycle & 282 & 303 \\
\hline Truck & 218 & 231 \\
\hline
\end{tabular}




\begin{tabular}{|l|c|c|}
\hline Bicycle & 128 & 128 \\
\hline Van & 86 & 116 \\
\hline Pedestrian & - & 259 \\
\hline Other & 336 & 158 \\
\hline Total & 2390 & 3444 \\
\hline
\end{tabular}

Table 1 - Final database Composition According to Vehicle Class and Road-User Type

Data collected in the 'Accident Level' of the database includes a variable that records the vehicle types involved in the accident, The vehicle type with the largest share of accidents (57\%) are Cars followed by more vulnerable road users such as Motorcyclists and pedestrians. The in-depth nature of the data allows information on small groups such as agricultural vehicles or Train/Trams to be recorded. This analysis is summarised in figure 1 .

Figure 1

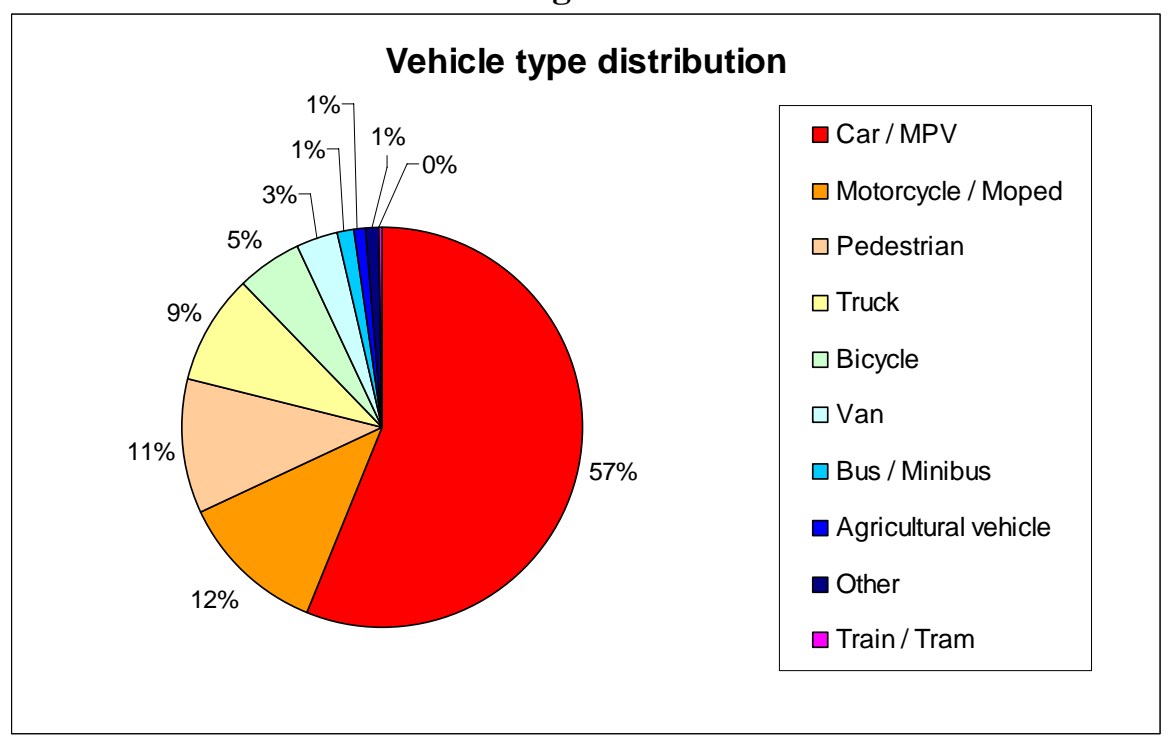

Figure 2 shows the proportion of single vehicle accidents in the database. Single vehicle accidents recorded in the database account for nearly $30 \%$ of all accident types, a total of 359 accidents. Within this Cars are the most prolific with nearly 3 quarters (74\%) of all single vehicle accidents; this is followed by motorcycles with a further $16 \%$ of all single vehicle accidents. Single vehicle accidents for both these high risk groups are shown as the proportion of accidents by the days of a week and shows a significant increase in fatal single vehicle accidents from Friday to Sunday inclusive. 


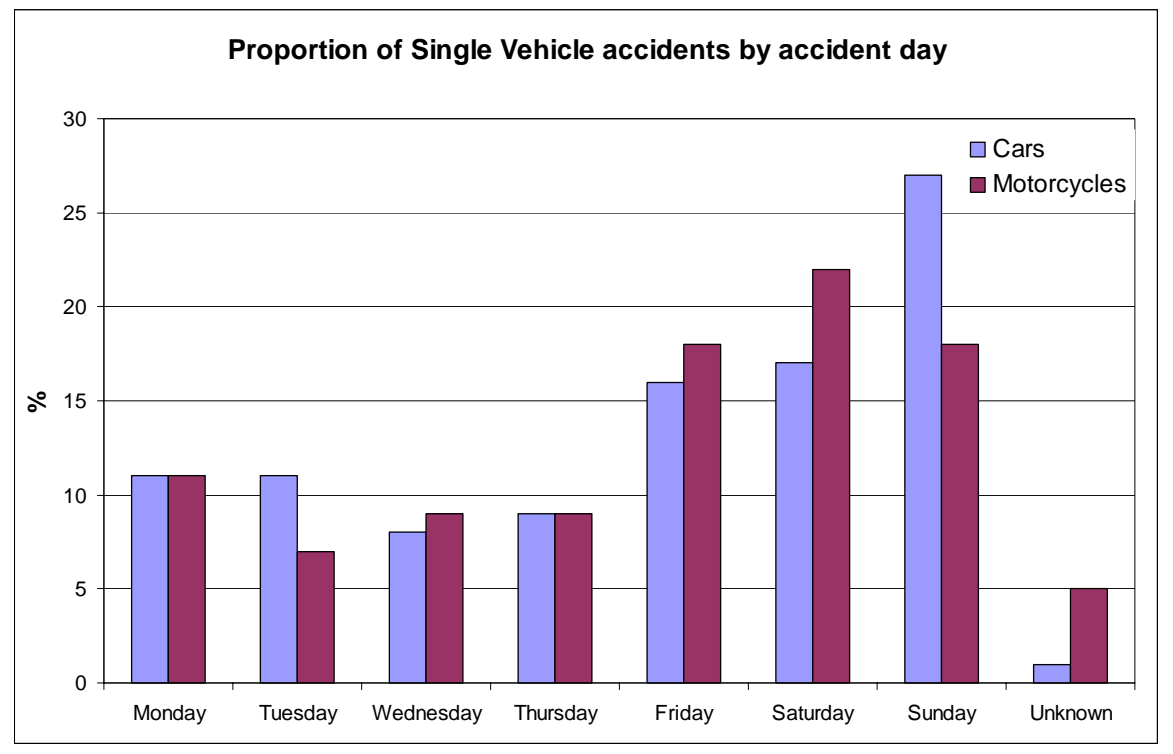

Figure 3 shows the age-banding for passenger cars in which a fatality occurred. Passenger cars built after 1990 are the most prevalent in the dataset ( 75\%) and the number of these where an occupant was fatally injured remains high mainly due to the comparatively modern vehicle fleets in all 7 partner countries contributing significantly to exposure. Cars built before 1980, despite their lack of passive and active safety systems, constitute only $1 \%$ of all vehicles that contain a fatally injured occupant.

Figure 3

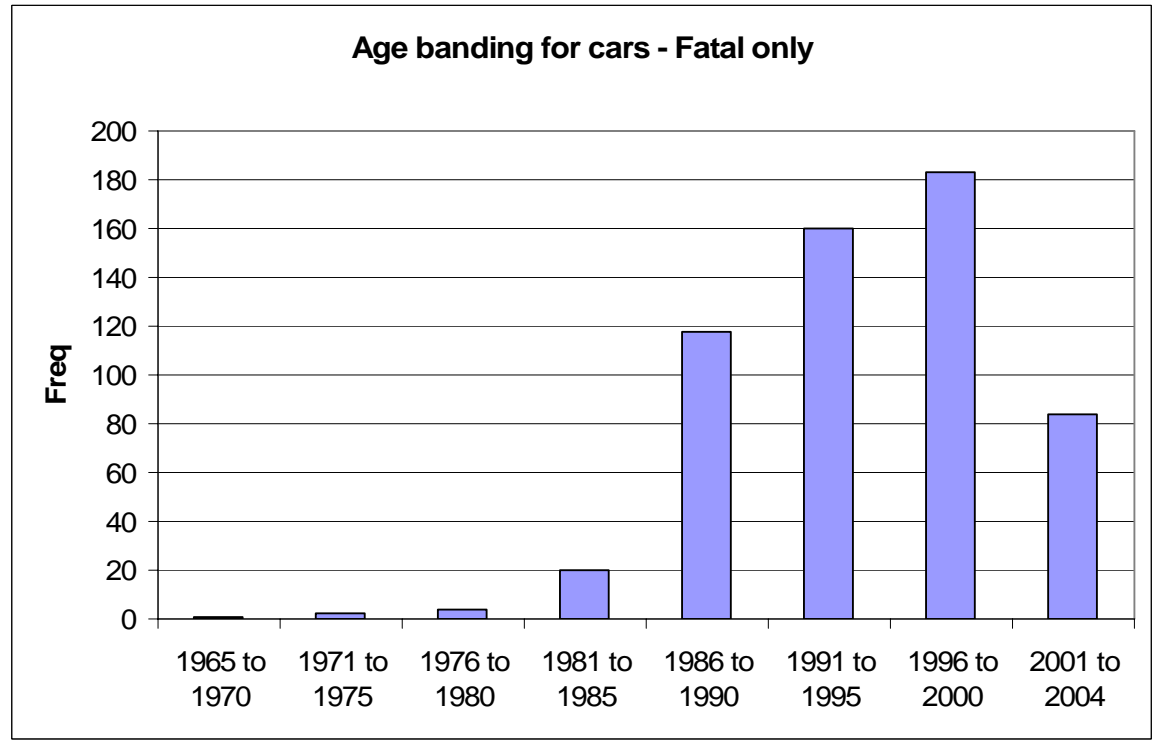

Figure 4 shows the age-banding for the fatally injured driver in the accident.

Figure 4 


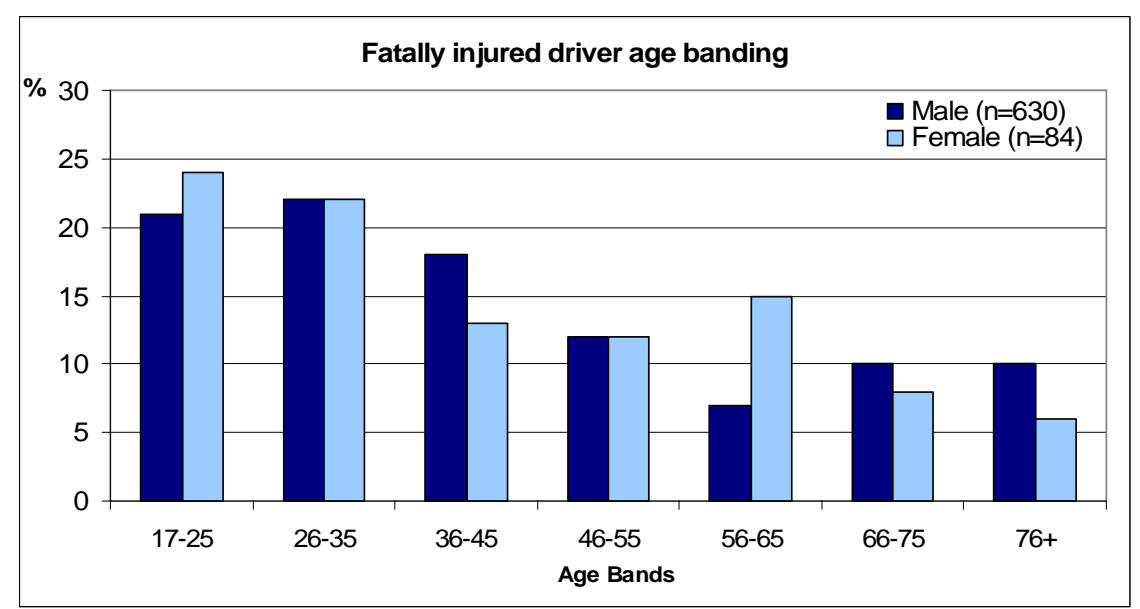

It is well understood that within the young novice driver population, and in particular males, risk taking behaviour is commonplace, this is a cause for concern across Europe and the results from the fatal sample show this to be particularly evident with a seven fold increase in the numbers of male drivers killed $(\mathrm{n}=630)$ compared to females $(\mathrm{n}=84)$

Figure 5 shows belt use for fatally injured passenger car drivers.

Figure 5

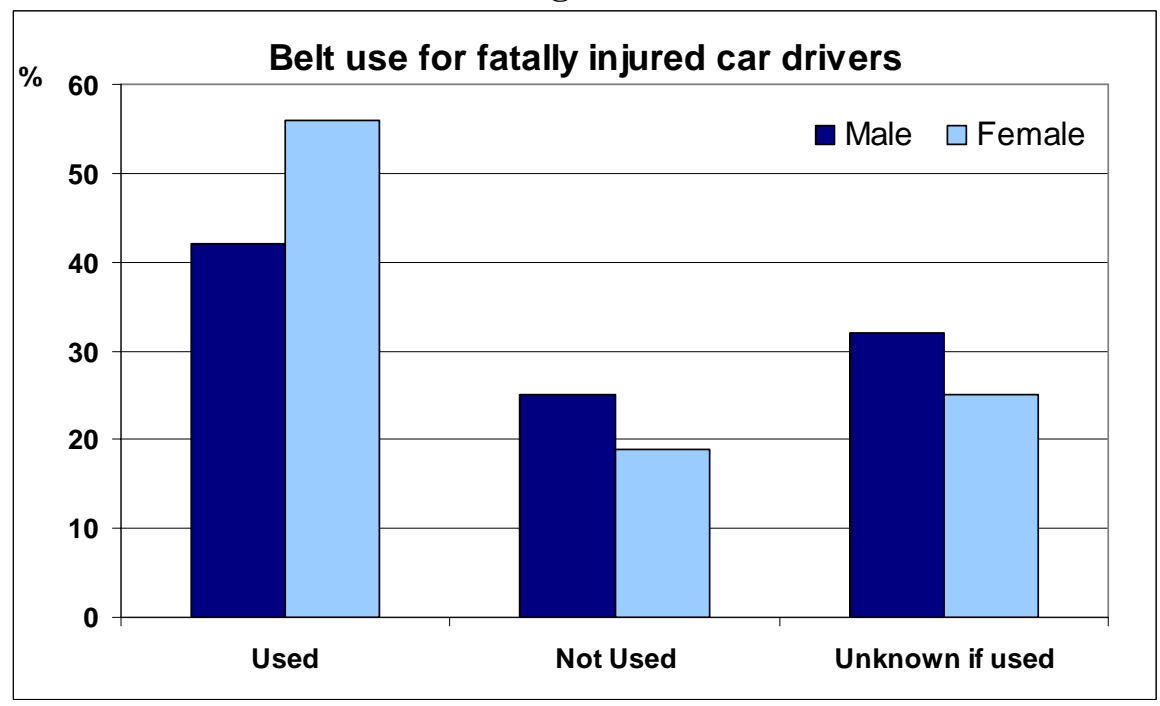

As can be seen in figure 5, approximately 50\% of all car drivers, both Male and Female, who were fatally injured, were belted. This result although initially encouraging differs significantly from the rates of belt usage estimated from observational studies of the general driver population.

Restraint systems recorded as 'Not Used' for fatally injured car drivers remains high with approximately $1 / 4$ of all drivers being unbelted, a slightly higher proportion of these being Male.

Figure 6 shows the body regions most severely injured (according to post-mortem reports) for passenger car drivers. 
Figure 6

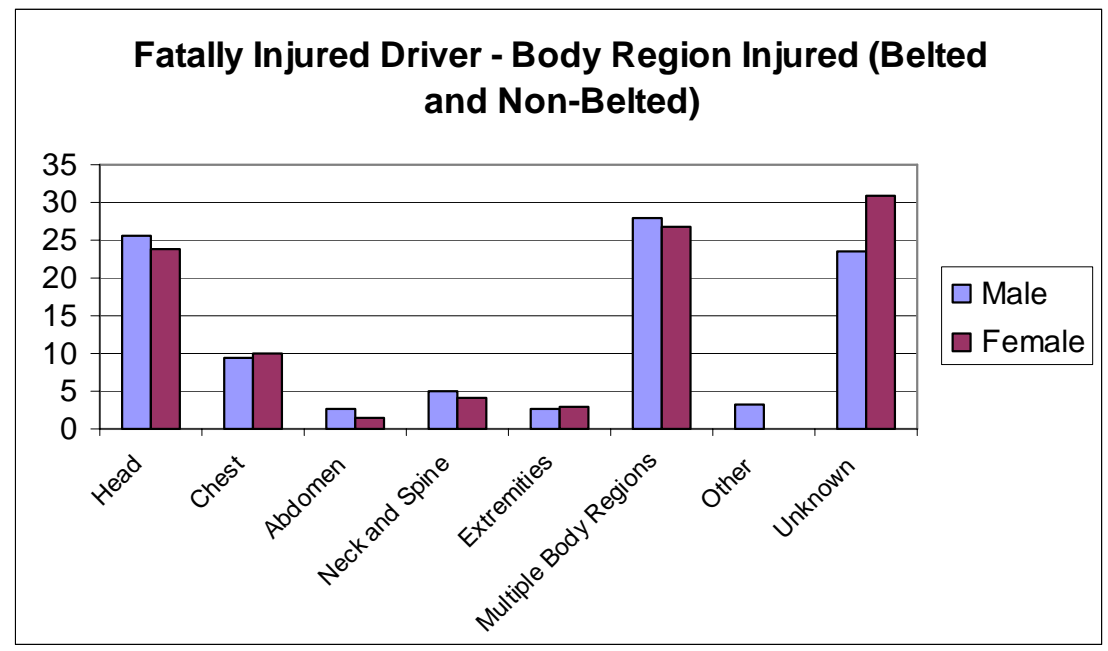

It can be seen that the head is the most common single body region injured for both belted and unbelted drivers - the next most common single body region being the chest although the rate is less half of that for head injuries.

In figure 7, prevalence of eSafety equipment fitment to vehicles is shown. This includes the numerous active safety systems installed in passenger vehicles for the purposes of collision avoidance.

Figure 7

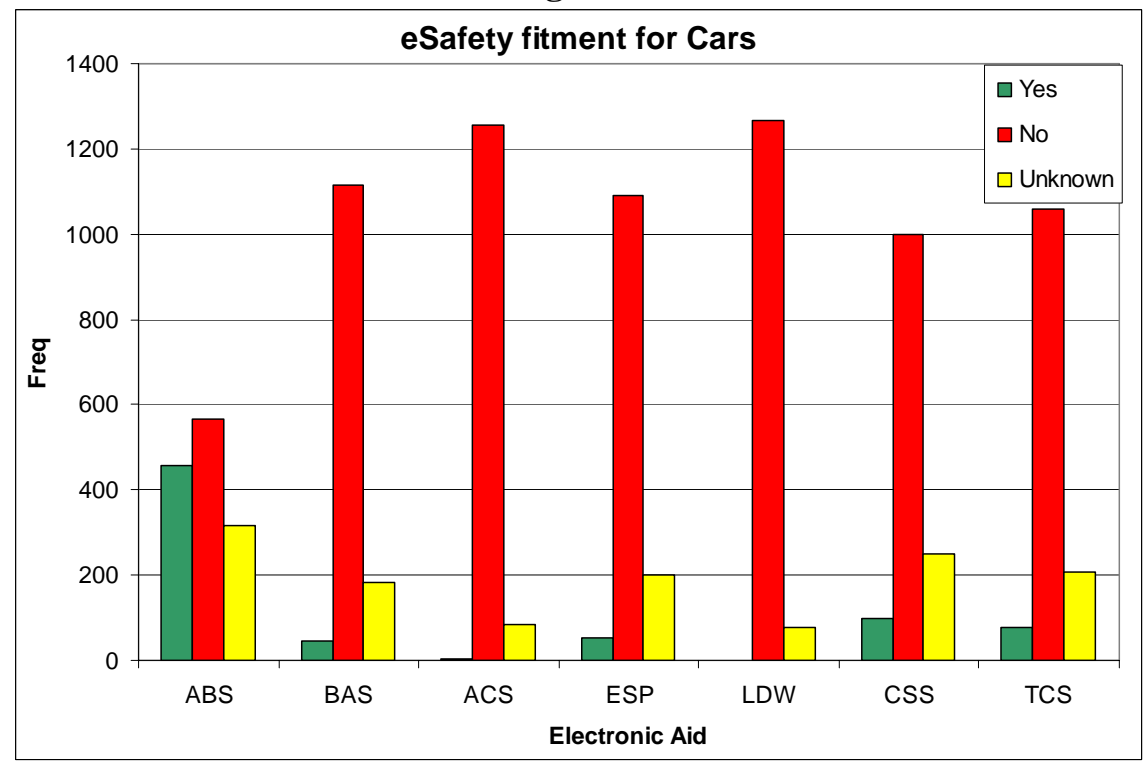

Considering single vehicle loss of control accidents account for $\sim 28 \%$ of all accident types then the lack of fitment of ESP (Electronic Stability Program) systems shows there is a need for this technology to be standard fit.

Emergent technologies such as Lane Departure Warning (LDW) and Active Cruise Control (ACS) currently have negligible impact on the recorded results, however a future proof dataset and data collection methodology will, in time, display similar results to those collected for the Anti Lock Brake (ABS) variable which is now mandatory fitment on all volume sale vehicles. 
Figure 9 shows the proportion of single vehicle accidents by EU Member State as included in the database.

\section{Figure 9}

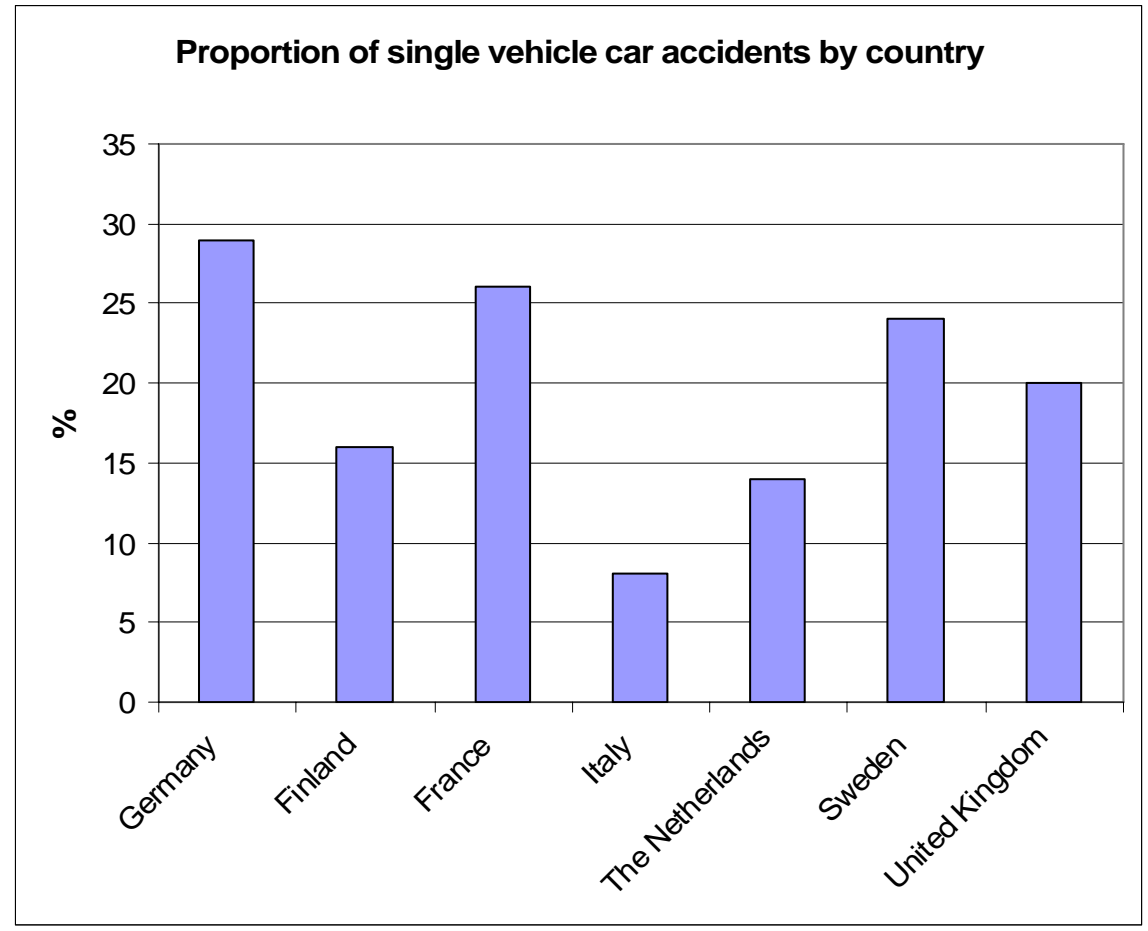

Single vehicle accidents attributable to cars account for slightly over $20 \%$ of the total accident population, a total of 266 accidents. The proportion of single vehicle accidents vary significantly from this average between the 7 countries represented in the sample. The situation in Italy for example shows that less than $10 \%$ of all accidents happen with only one vehicle where as in Germany this figure is nearly $30 \%$, Road layout, Road infrastructure, Traffic volumes and general driving behaviour are possible explanations for the difference shown.

Finally figure 10 shows the first contributory event leading up to the fatal accident occurring.

Figure 10

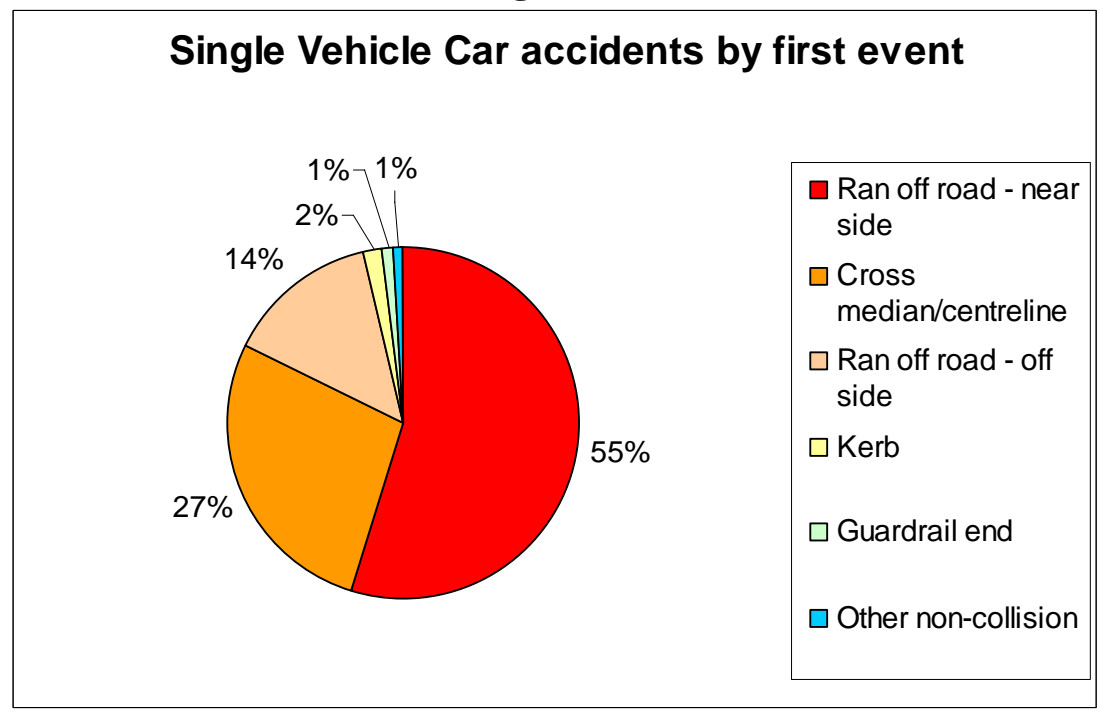


What may cause a vehicle to lose control or where the loss of control stemmed from is crucial to understanding the sequence of events in a single vehicle accident. Running off the road to the nearside, that is without crossing an oncoming carriageway lane, accounts for slightly over half of the first events recorded for SVA, Running off the road both to the nearside and offside accounts for nearly $70 \%$ of single vehicle first accident events for cars.

\section{DISCUSSION}

In-depth crash databases contain the necessary post-crash information for analyses of causal factors in crashes. They often contain the detailed injury and vehicle crash data generally gathered by teams of medical and technical experts and police specialists soon after a severe incident. These combined details of road crashes are indispensable for input to road safety regulation.

This project demonstrates (i) the efficient use of existing high quality and under-utilised information resources and the use of such to understand crashes and develop effective countermeasures, and (ii) the development of a novel data capture and categorisation system with the use of existing infrastructure to collect high quality, multidisciplinary crash causation data. Crash causation databases traditionally contain the necessary details of the pre-crash data, where the other databases either contain hardly any data on the pre-crash phase of the incidents or only post-crash data. Self-evidently pre-crash data are indispensable for the analysis of effective countermeasures to prevent road crashes. Since the focus on the relevant pre-crash data generally differs for incidents of different road users, there are activities on crash causation data gathering for car crashes, for motorcycle crashes and pedestrian crashes; the latter two for obvious reasons also include data that are relevant for the causation of injuries. Some national crash causation studies have been carried out in several Member States, either in connection with the in-depth injury causation work (e.g. Medical University of Hannover) or by the police in routine recording of incidents and casualties in the national crash database system (e.g. Great Britain). Additionally, some previous studies have been conducted: The Association of European Car Manufacturers (ACEA) has conducted a European Accident Causation Survey on car crashes with financial support from the European Commission. The focus on research interests of the car manufacturers for this study on the pre-crash conditions of car crashes is quite understandable, since improvement of pre-crash conditions may focus more on road infrastructure as much as vehicle design. However, great care must be taken that any database is independent of the major stakeholders if it is to be used to inform public policy and evaluate the effectiveness of safety systems in an impartial way.

Future directions in pre-crash technology, including that undertaken by the eSafety group involve the development and implementation of many technologies that have the potential for casualty reduction and a representative research in-depth database is needed to ensure that strategic decisions over systems development are directed by estimates of casualty reduction under real-world conditions.

The results of this study are included for demonstration only. They represent an initial analysis which is intended to provide an overview of the type of data that is contained within the database. Further more rigorous statistical analyses of data will be undertaken in the coming months now that the database has been finalised and subjected to quality control reviews. These analyses will be reported on in the coming months.

\section{REFERENCES}

[1] Association for Chief Police Officers (ACPO) (2004). The Road Death Investigation Manual. Available from: http://www.acpo.police.uk/asp/policies/Data/rd_death_manual_v2_2004_updated_19x04x04.pdf 
[2] Clarke, D., Ward P. \& Truman W. (2002) In-depth accident causation study of young drivers. Prepared for Road Safety Division, Department for Transport, Local Government and the Regions, TRL Report TRL542 found 2005-07-27 at http://www.trl.co.uk/static/dtlr/pdfs/TRL542.pdf

[3] eSafety (2006); http://europa.eu.int/information_society/doc/factsheets/048-esafety.pdf

[4] European Commission (2005a). Accessed online [9 December 2005] from: http://europa.eu.int/comm/transport/road/roadsafety/index_en.htm

[5] European Commission (2005b). Accessed online [9 December 2005] from: http://europa.eu.int/comm/transport/road/figures/accidents/quickindicator/index_en.htm

[6] European Transport Safety Council (ETSC) (1997). Transport Accident Costs and the Value of Safety. ETSC, Brussels.

[7] European Transport Safety Council (ETSC) (1999). Risk of Death and Injury of Travel in the European Union. Accessed online [9 December 2005] from: http://www.etsc.be/documents/pre_8jun99.htm

[8] European Transportation Safety Council (ETSC) (2001) Transport Accident and Incident Investigation in the European Union. Found 2005-07-27 at http://www.etsc.be/documents/accinv.pdf

[9] Nakahara S and Wakai S (2001). Underreporting of traffic injuries involving children in Japan. Injury Prevention 242 2001;7:242-244

[10] SafetyNet (2004). WP5 Workshop Report "Establishing Requirements for a New European In-Depth Accident Causation Database”, Oct 04. Available from http://safetynet.swov.nl/index.htm

[11] Sandin, J. \& Ljung, M (2004) Crash investigations for active safety - Meeting new demands on investigation methodology. Presented at the 1st International Conference on ESAR - Expert Symposium of Accident Research, Hannover, Germany

[12] Thomas, P et al; Designing the Road Safety Observatory. Journal of Injury Control and Safety Promotion Vol. 12 No 4 pp251-253

[13] Global Road Safety Partnership (GRPS) (2006). Available from: http://www.grsproadsafety.org/?pageid=107

\section{ACKNOWLEDGEMENTS}

The authors gratefully acknowledge the funding for this project which is co-financed by the European Commission, Directorate-General Transport \& Energy. 